\title{
Juan Trías Vejarano, Del antiguo régimen a la sociedad burguesa
}

(2019) Tecnos

Madrid, 272 pp.

\author{
Victoriano Martín Martín* \\ Universidad Rey Juan Carlos \\ victoriano.martin44@gmail.com
}

\section{Cita recomendada:}

Martín Martín, V. (2019). Juan Trías Vejarano, Del antiguo régimen a la sociedad burguesa. Eunomía, Revista en Cultura de la Legalidad, 18, pp. 437- 448

doi: https://doi.org/10.20318/eunomia.2020.5293

Est autem contractus, ut politice loquar, quaelibet conventio inter aliquos constituta, et commiuni deliberatione firmata (Alfonso Fernández de Madrigal, De optima politia).

Mientras comenzaba a escribir este papel, María José Villaverde nos informa de la triste noticia de la muerte de Juan Trías. El martes 10 de septiembre la profesora Villaverde publicó una necrológica preciosa, que rebosaba cariño y agradecimiento. Una síntesis excelente del pensamiento y de la trayectoria intelectual del profesor Trías Vejarano. Una síntesis que me ha ayudado a ordenar el análisis y la crítica del libro, que nos ocupa. Señalaba María José dos aspectos, que podían haber condicionado su obra; su «anticlericalismo militante» y la necesidad de «contextualizar siempre». El relativismo inherente a su afán de «contextualizar siempre» chocaba con mi concepción metodológica popperiana, cuyas características fundamentales serían el absolutismo filosófico, siguiendo la terminología de Mark Blaug, y el falsacionismo de Karl Popper. Tengo que manifestar que al encontrarme con los términos "formaciones sociales» en la primera página del libro, busqué en mi biblioteca el libro de Marta Harnecker, Conceptos elementales del materialismo histórico, pero todo aquello, a estas alturas se me caía de las manos. Antes que nada quiero resaltar la gran erudición

* Catedrático de Historia del Pensamiento Económico de la Universidad Rey Juan Carlos. 
desplegada por Juan Trías en esta obra así como la utilización de los textos originales de los autores; como veremos, no creo que se haga justicia con Suarez. Por lo que se refiere al resto de los autores estudiados, creo que tanto Bodino como Altusio tienen un rigor analítico muy inferior a los grandes pensadores escolásticos que vamos a tratar aquí; en cuanto a Grocio, el padre Alonso Getino, en el tomo tercero de su edición de las Relecciones Teológicas del Maestro Fray Francisco de Vitoria (1935), ha realizado las concordancias entre Vitoria y Grocio, si se hicieran las de Vázquez de Menchaca y Grocio, se pondría en entredicho la originalidad del autor holandés.

No soy especialista en teoría político-social, ni tan siquiera en teoría política. Me acerqué a la Teoría del Estado en la escolástica española de los siglos XVI y XVII desde la Nueva Economía Institucional; por tanto estas son mis limitaciones. Ahora bien, creo que conozco tanto la Teoría del Estado de los escolásticos como la de Thomas Hobbes; de ahí que sea este el ámbito en el que centraré estos comentarios ${ }^{1}$.

La comparación entre la Teoría del Estado de Hobbes y la de la escolástica española desde los aspectos que parece son el fundamento de la teoría de Hobbes, esto es, su concepción de la naturaleza humana, su concepto de estado de naturaleza y su teoría del contrato, será el objeto fundamental de la crítica que me propongo. No cabe duda que existen grandes diferencias entre Hobbes y los escolásticos. En primer lugar, Hobbes no fue ni clérigo ni profesor de Universidad; los escolásticos eran teólogos y académicos, la mayoría pertenecientes a órdenes religiosas, dominicos y jesuitas; sus enseñanzas de teoría del Estado y de los derechos de propiedad generalmente eran impartidas en el ámbito de sus clases de Teología. Hobbes fue el primer filósofo político, propiamente dicho. Los escolásticos tenían una concepción democrática del poder político, la de Hobbes era absolutista. El contrato en los escolásticos lo establecen los ciudadanos y el Soberano que se compromete a garantizar las vidas y las propiedades de los subditos así como a velar por el bienestar de la Comunidad; para todo esto le entregan el poder; en el contrato está presente la necesidad del consentimiento de los ciudadanos para todas aquellas medidas que adopte el Soberano si las mismas afectan a su bienestar o al de la Comunidad, tales como la alteración del valor de la moneda, o la imposición de nuevos tributos; esto es, los ciudadanos de lo escolásticos, conscientes de que el príncipe es una criatura suya, cuya existencia es impensable al margen de su voluntad, jamás renuncian a su libertad y soberanía para poder remover al príncipe si éste no cumple con la función que se le encomendó. El establecimiento del poder político, a través del concepto de libertad regulada frente al desenfreno sin normas, intenta reducir el dominio de cada individuo a una esfera, garantizada por la justicia, en que no pueda perjudicar a los otros.

En el caso de Hobbes, sin duda, mucho más claro, sintético y explícito, el contrato lo establecen solo los ciudadanos para entregar todo el poder al Soberano y no aparece rastro de la teoría del consentimiento, pues

el único modo de erigir un poder común, capaz de defenderlos de la invasión extranjera y las injurias de unos a otros [...] es conferir todo su poder y fuerza a un hombre o a una asamblea de hombres, que pueda reducir todas sus voluntades, por

\footnotetext{
${ }^{1}$ La comparación de Hobbes con San Agustín la he tomado del capítulo 3 de mi libro (2002). El Liberalismo Económico. Madrid, España: Editorial Síntesis. El grueso del análisis de la Teoría del Estado de los Escolásticos en relación con Hobbes la he tomado de mi artículo (2011). Teoría del Estado y Derechos de Propiedad en la Escolástica Española del siglo XVI. Un antecedente de la Nueva Economía Institucional. Revista del Instituto de Estudios Económicos, (2), pp. 81-110.
} 
pluralidad de veces, a una voluntad [...] y someter así sus voluntades, una a una, a su voluntad, y sus juicios a su juicio (Hobbes, 1991, p. 120).

En el capítulo 1, Trías, refiriéndose a «la organización política, como una construcción, netamente diferenciada, a través de un contrato singular, distinguen también la obra de Hobbes de los autores anteriores». Pues bien, es cierto que la exposición de Hobbes es mucho más concisa y evidente,

es más que consentimiento o concordia; es una verdadera unidad de todos ellos en una e idéntica persona hecha por pacto de cada hombre con cada hombre, como si todo hombre debiera decir a todo hombre: autorizo y abandono el derecho a gobernarme a mí mismo, a este hombre, o a esta asamblea de hombres, con la condición de que tú abandones tu derecho a ello y autorices todas sus acciones de manera semejante (Ibid.)

Ahora bien, quiero llamar la atención sobre la originalidad de la teoría del contrato; como aparece en el frontispicio de este papel, la teoría del contrato político como constitutivo de la organización social y del Estado parece estar presente en la tradición escolástica al menos desde Alfonso Fernández de Madrigal (1401-1455).

Trías en el mismo capítulo, apartado 1.5 no duda en afirmar que «lo novedoso en Hobbes, y que rompe con el pensamiento de los autores» anteriores «es el punto de partida, que es el hombre en cuanto individuo [...] a partir de las determinaciones de la naturaleza humana». Pero tales determinaciones de la naturaleza humana son prácticamente idénticas al concepto de naturaleza humana en San Agustín (pp. 354-430), quien diseñó la forma en que Occidente ha pensado sobre la naturaleza humana con su exposición de la psicología del hombre caído o pecador. Agustín cree que la mayoría de los hombres son irredimibles, y que esto ha sido siempre verdad en el pasado y seguirá siendo verdad hasta el fin del mundo. Pues bien, la psicología del hombre caído o pecador es crucial para entender las instituciones de la sociedad humana, como la propiedad, la familia, la esclavitud y sobre todo el orden político. Otro tanto ocurre con el estado de naturaleza.

La principal característica que identifica al hombre caído es el egoísmo en forma de codicia, esto es el deseo de dinero y posesiones. La libido es el término genérico que emplea Agustín para designar todos los deseos mundanos y la define como el apetito por el que son preferidos los bienes temporales a los eternos. Todo deseo terreno es una forma de libido, «la ira es el deseo de venganza, la avaricia es el deseo de dinero y la inclinación al poder es el deseo de dominio». Para Agustín, una de las tres formas primarias de libido es la codicia, avaricia, que es el apetito desordenado e insaciable de bienes materiales, especialmente la riqueza -las otras dos son la libido dominandi y la lujuria. No existe límite a los deseos del hombre depravado, pues su vida consiste en una búsqueda desasosegada por la consecución de un objeto detrás de otro. La avaricia, por su propia naturaleza, no puede tener límite. Así se refiere Agustín al hombre caído:

Buscabas haciendas, deseabas ser dueño de tierras, no querías vecinos; habiéndote desecho de unos, ansiabas engullir a otros, y tanto abrías las fauces de la avaricia, que llegabas hasta la playa, y en llegado que llegabas a ella, deseabas las islas. Adueñado de la tierra, quizá quieres asir el cielo (San Agustín, 1982, pp. 731-732).

Señala Agustín que para estos hombres que el mundo considera «de gran consejo y prudencia», empeñados en la búsqueda estéril de felicidad mediante la satisfacción de un número infinito de deseos, todos los medios, todas las artimañas para acumular bienes y dinero son legítimos. Así se dirige Agustín, ahora irónicamente, al hombre caído recriminándole: «Tú, sin duda, hombre de gran 
consejo y prudencia...robas al hombre y tú te quejas del ladrón. Lo que tú haces con otro, temes te suceda, y no te corriges del detrimento que perpetras» (San Agustín, pp. 701-702).

Ahora bien, esta codicia desenfrenada no está limitada al rico, pues los hombres en general, «se mueven más por la avaricia que por la habilidad; y aun entre los mismos artistas es raro encontrar quien no venda su arte por dinero» (San Agustín, p. 419).

Tampoco los más pobres están libres del pecado de la codicia, pues su envidia del rico y la amargura por su pobreza les llevan a desear los bienes temporales tanto como el rico. Existe un paralelismo claro entre la búsqueda desasosegada del hombre para satisfacer sus necesidades, que nos describe Agustín, y el hombre de Hobbes, que emplea toda su vida esforzándose en colmar un deseo detrás de otro. La diferencia estriba en que mientras Hobbes acepta el desasosiego y la búsqueda sin fin del hombre por satisfacer sus necesidades como algo natural e inevitable, Agustín lo considera como una insensatez pecaminosa natural solamente para el hombre caído. De la misma forma, la descripción gráfica de Hobbes del bellum omnium contra omnes nos recuerda el modo en que Agustín pinta las consecuencias de la competencia feroz por los bienes, inevitablemente escasos, por parte de hombres egocéntricos impulsados por deseos infinitos (Deane, 1963, pp. 46-47).

Si el hombre natural de Hobbes no está nunca libre de preocupación y desvelo por impedir que les sean arrebatadas sus riquezas, la suerte de los hombres mundanos de Agustín tampoco es muy envidiable, pues «el más poderoso busca al más débil, y le busca para oprimirle y sólo porque tiene lo que ha de quitarle. Le ve, sometido a él, soportar tribulaciones únicamente por causa de lo que tiene; así el poderoso acumula junto a sí aquello por lo que el débil soporta tribulación» (San Agustín, 1982, p. 301).

Los hombres de la ciudad terrena superan en egoísmo y en crueldad la conducta del bellum omnium contra omnes de los individuos de Hobbes: su egoísmo desenfrenado y su insaciable codicia son inevitablemente autodestructores, pues en medio del fragor del conflicto de egoísmos y codicias, la imposibilidad de satisfacer el más mínimo deseo conduce a la miseria, al sufrimiento y a la frustración. Si el egoísmo en forma de codicia, el deseo de dinero y posesiones, es la primera característica que identifica al hombre caído, su segunda e igualmente importante cualidad es a la que repetidamente se refiere Agustín como la pasión de dominio sobre otros hombres o el deseo de poder -libido dominandi-. La libido dominandi está asociada con el amor a la gloria, el honor y el hambre de alabanza. Lo mismo que la avaricia, el deseo de ejercer el poder y la dominación es común a todos los hombres.

El tratamiento de Agustín de la libido dominandi de nuevo nos recuerda el retrato de Hobbes del hombre natural y su:

deseo perpetuo e insaciable de poder tras poder que sólo cesa con la muerte. Y la causa de ello no es siempre esperar un goce más intenso que el ya obtenido ni tampoco ser incapaz de contentarse con un poder moderado. En realidad, el hombre no puede asegurarse el poder y los medios para vivir bien, que actualmente tiene, sin la adquisición de más [...] Y cuando todo eso se cumple, surge un nuevo deseo; en algunos de fama por nuevas conquistas; en otros de ocio y placer sensual; en otros de admiración, o de ser ensalzados por descollar en algún arte o en otra capacidad de la vida (Hobbes, 1991, p. 70). 
Con todo, hay una diferencia entre los dos pensadores. Para Hobbes, el deseo que tiene el hombre de gloria es secundario, su impulso básico es el instinto de autoconservación y seguridad, y el impulso adquisitivo, que es uno de los mayores vehículos por los que este instinto básico se satisface. Agustín, por su parte, contempla el deseo de dominio y de gloria como un impulso independiente, tan básico para el hombre como la codicia.

Pues bien, ante este panorama de hombres egoístas y avariciosos, hambrientos de poder, dispuestos a destruirse los unos a los otros en una lucha feroz por el propio engrandecimiento, Agustín, a fin de que no reine la anarquía, propone como remedio el Estado, cuya finalidad consiste en la defensa de los derechos de propiedad mediante el mantenimiento del orden y la paz o, mejor, la ausencia o, al menos, la disminución de la violencia. El estado también es un orden coercitivo mantenido por el uso de la fuerza y confiando con el miedo al castigo como su mayor sanción para la sumisión a sus mandatos. El objetivo fundamental del Estado es disuadir a los ciudadanos de realizar ciertas clases de actos nocivos y delictivos. Es una institución correctiva, lo mismo que la propiedad privada, la esclavitud y otras formas de dominación del hombre sobre el hombre.

Sin Estado reinaría la anarquía, y los hombres egocéntricos, avariciosos, hambrientos de poder y lujuriosos se destruirían unos a otros en una lucha feroz por el auto engrandecimiento. Como puede observarse, este estado de cosas descrito por Agustín, como consecuencia de la caída, es prácticamente igual que el estado de naturaleza que nos dibuja Hobbes. Por consiguiente, el Estado es un orden externo, coercitivo, represivo y correctivo. Ciertamente esta concepción del Estado parece esencialmente moderna, al menos tan moderna como la de Hobbes, salvando las distancias, pero sorprende especialmente encontrarla en un filósofo cristiano del siglo V. Agustín señala que: «la función de la ley temporal es asegurar que los hombres puedan poseer las cosas que podemos llamar "nuestras" por una temporada y que los otros codician con impaciencia, con la condición que la paz y la sociedad humana sean preservadas, entre tanto que pueden ser preservadas las cosas mundanas» (San Agustín, 1982, p. 259). La ley determina que los ciudadanos puedan poseer legítimamente, y por las sanciones asegura a cada ciudadano el disfrute de sus posesiones. La ley, lo mismo que en el caso de Hobbes, opera a través del instrumento del miedo. La sanción por medio de la cual el Estado intenta asegurar la conformidad a la conducta prescrita por las leyes consiste en la habilidad de privar al ofensor de una o más de sus posesiones, su propiedad, su libertad, su ciudadanía o en última instancia su vida (Deane, 1963, pp. 139-140).

Finalmente para concluir estas reflexiones sobre la comparación de la concepción del Estado de Agustín y Hobbes, me voy a referir a la definición de Estado de Agustín; comienza tomando prestada la definición de Estado dada por Escipión en La Republica de Cicerón, en que se identifica populus con res publica, esto es, populum autem non omnem coetum multitudinis, sed coetum iuris consensu et utilitatis communione sociatum ese determinat, pueblo no es cualquier grupo de gente, sino «la asociación de personas basada en la aceptación de las leyes y en la comunión de intereses»(San Agustín, 1982, p. 121). Pero Agustín había prometido a sus lectores su propia definición de Estado, promesa que cumple cuando afirma que civitas, quae nihil aliud est quam hominum multitudo aliquo societatis vinculo colligata, "una ciudad, que no es otra cosa que una multitud de hombres unidos entre sí por algún vínculo social»(Ibid., p. 161). Aunque en estas definiciones de ciudad, civitas, una nomenclatura que aparece en Hobbes -pues «la multitud así reunida en una sola persona se llama republica, en latín civitas» (Hobbes, 1991, p. 120) - que el propio Agustín, a veces, denomina populus o res publica, no aparece la 
palabra contrato, pero el hominum multitudo aliquo societatis vinculo colligata es prácticamente idéntico al concepto de contrato de Hobbes.

Retomamos ahora la teoría del poder político que dejamos iniciada más arriba de Alfonso Fernández de Madrigal, El Tostado; para él el poder político, cuyo objetivo es garantizar el bienestar de la comunidad, reside en Dios, quien trasmite dicho poder inmediatamente a los súbditos, que a su vez constituyen lo que designamos con el concepto abstracto de comunidad, que es la que elige al príncipe. No parece arriesgado señalar a nuestro autor como uno de los defensores del contrato político como constitutivo de la organización social y del Estado. Así parece deducirse de un párrafo en latín, que traducido de una forma un poco libre vendría a decir: "es pues un contrato, políticamente hablando, cualquier convención establecida entre algunos, y confirmada por decisión de todos» (est autem contractus, ut politice loquar, quaelibet conventio inter aliquos constituta, et commiuni deliberatione firmata).

El grueso de la filosofía política de El Tostado la encontramos en su Relección De optima politia, donde intenta presentar el sistema de gobierno ideal. En su intento de diseño de este tipo de gobierno tiene muy presente la realidad de la condición humana, de la que se muestra un profundo conocedor. Puesto que no se trata solo de diseñar el mejor sistema de gobierno, hay que asegurar su supervivencia. Es necesario instaurarlo y conservarlo. De ahí la necesidad de asegurar la paz y el bienestar de la comunidad. A fin de asegurar la instauración y conservación del mejor sistema de gobierno es necesario conocer bien la naturaleza humana, y Alfonso Fernández de Madrigal, lo mismo que San Agustín, es consciente de la debilidad de la condición humana, de sus tendencias pasionales viciosas y de sus sentimientos perversos, características que deben estar presentes a la hora de diseñar una organización social capaz de resolver los problemas de los hombres. Esta concepción agustiniana pesimista de la naturaleza humana le lleva a desaconsejar el Evangelio como norma positiva para la Republica temporal.

De acuerdo con tales supuestos, El Tostado más que el mejor sistema de gobierno intenta encontrar el más conveniente. Al menos implícitamente, de la doctrina de Alfonso Fernández de Madrigal, se desprende la teoría del consentimiento, que significa que el gobernante no puede tomar decisiones que afecten a la comunidad sin el consentimiento del pueblo, una doctrina que se venía defendiendo en el ámbito de la Universidad de Paris. Dejando de lado algún ejemplo más temprano como la Bula de Inocencio III de 5 de abril de 1199, Quanto personam tuam, que defiende el pleno contenido metálico de las monedas y la necesidad del consentimiento del pueblo en caso de alteración. Al menos desde el siglo XIV venía siendo doctrina común. Y la elevarían a la categoría de norma los escolásticos españoles en los siglos XVI y XVII.

Al analizar el origen y la necesidad del Estado en los escolásticos españoles en los siglos XVI y XVII, son de capital importancia los conceptos de naturaleza humana, de pacto y de estado de naturaleza, como en el caso de Hobbes. Aquí son claves las aportaciones de Francisco Suarez y de Luis de Molina y su concepción agustiniana de la naturaleza humana: la propensión de los individuos a buscar el propio interés y la flaqueza moral de los hombres en el estado de naturaleza caída. Pero existe otra justificación más aristotélica y tomista, esto es la sociabilidad natural de los hombres, que se reencarna en la obra de Francisco de Vitoria. Nos encontramos con la posición intermedia de Domingo de Soto; y tenemos que referirnos también a la obra del franciscano Alfonso de Castro. Es necesario resaltar las aportaciones de Fray Luis de León, que en su Tratado sobre la ley realiza una defensa del Estado y de la propiedad homologable a la David Hume, y finalmente 
las de Vázquez de Menchaca, un jurista laico, que tiene una justificación utilitarista del Estado y que con un razonamiento completamente laico se adelanta a Grocio en el concepto de derecho natural.

La necesidad y en consecuencia el diseño de la sociedad política surge de un presunto "estado de naturaleza» a través del consentimiento. Es cierto que la mayoría de los autores no se refieren explícitamente al "contrato social» como origen del Estado, pero su razonamiento para explicar el origen del poder político implica al menos de forma implícita la teoría del contrato, pues dice Francisco Suárez S.J. (1548-1617): "La multitud humana [...] por un deseo especial o consentimiento general se reúne en un cuerpo político con un vínculo de sociedad y para ayudarse mutuamente» (Suárez, 1967, p. 202); y todavía de una forma más clara y explícita cuando se refiere al origen del derecho de gentes, como antecedente del derecho internacional, ya que «el género humano [...] dividido en distintas comunidades [...] convino que, como por un pacto y consentimiento común, observasen entre sí algunos derechos comunes» (Suárez, p. 203).

Todos estos autores tenían el concepto de estado de naturaleza, estado de naturaleza caída, y Luis de Molina S.J. (1536-1600) se refiere a la condición de la humanidad en el estado de naturaleza caída como aquella situación en que se encuentran los hombres después del pecado y antes de la formación de la sociedad política, en que los individuos están «llenos de afectos depravados y de pasiones». Pero lo que sí aparece de una forma explícita es la necesidad del consentimiento para que se produzca la transición a la sociedad política.

Todos ellos, sin mencionar de forma expresa el estado de naturaleza, se refieren a la condición original o natural como un estado de libertad, igualdad e independencia. Francisco de Vitoria O.P. (1483-1546) afirma que «antes de que convengan los hombres en formar una ciudad ninguno era superior a los demás» (De Vitoria, 1960, p. 159). Y Suárez reconoce que la dificultad principal para explicar el origen del poder político radica en que «este poder por sola la naturaleza de la cosa no reside en ningún hombre en particular sino en el conjunto de los hombres [...] y es que por naturaleza todos los hombres nacen libres y por eso ninguno tiene jurisdicción política sobre otro» (Suárez, 1967, pp. 201-202).

Vitoria se refiere a la sociabilidad natural del hombre y al poder político como algo natural a la convivencia humana. Fundamenta la organización social en la frágil naturaleza del hombre que no puede subsistir sin la colaboración de sus semejantes a través de la vida en sociedad, pues la naturaleza «concediendo al hombre la razón y la virtud, le dejó frágil, débil y pobre [...] como arrojado de un naufragio, [...] para subvenir a estas necesidades fue necesario que los hombres [...] viviesen en sociedad y se ayudasen mutuamente» Nitoria, 1960, pp. 154-155). Porque la vida «desplegada en soledad no podría menos de ser calificada de triste y desagradable» (Ibíd., p. 156). Nótese la semejanza de las palabras de Vitoria en negrita con la descripción que hace Hobbes de la vida del hombre en el estado de naturaleza, que «es solitaria, pobre, desagradable, brutal y corta» (Hobbes, 1991, pp. 107-108).

Como da a entender Suárez, si «los hombres por su naturaleza son libres y no están sujetos a nadie» debieron existir razones poderosas que les aconsejaron dejar de lado sus libertades naturales. "Como sucedió que, sencillamente, si consideramos lo que existe en la naturaleza de la cosas algunos hombres puedan gobernar a otros y colocarlos bajo una genuina obligación por medio de leyes que ellos mismos aplican» (Suárez, 1967, p. 197). Y Domingo de Soto afirma «que aunque los hombres hayan sido hechos naturalmente libres, sin embargo por 
instinto de la misma naturaleza, como animales sociales que son, ponen al frente de sí reyes y príncipes, para satisfacer así su deseo natural de conservación, y para que, obedeciéndoles, vivan más seguros y felizmente» (De Soto, 1967, p. 303).

Tanto Suárez como Molina, partiendo de una concepción de la naturaleza humana tan pesimista y sombría como la de San Agustín, introducen un nuevo argumento para justificar el origen del Estado, dan una vuelta al análisis optimista de la racionalidad y moralidad humanas; lo que les lleva a concluir que si los hombres hubieran permanecido en las comunidades naturales y prepolíticas sin someterse al imperio del derecho positivo, sus vidas se habrían visto limitadas por la creciente injusticia e incertidumbre. En palabras de Luis de Molina:

Después del pecado [...] los hombres se han vuelto más perezosos y débiles para el trabajo, estando llenos de afectos depravados y de pasiones [...]. Supuesta la malicia y la imbecilidad de los hombres subsiguiente a la pérdida de la justicia original [se hace necesario vivir] en un Estado íntegro y perfecto para que pueda conservarse entre los hombres la paz, la seguridad y la justicia. Ya que [...] con el poder del Estado cada uno se halla mejor defendido contra las injurias de los demás y son más fácilmente perseguidos y castigados los malhechores y facinerosos [...] y como quiera que las pasiones del hombre después del pecado están inclinadas al mal y en la juventud demuestra la experiencia que casi todos se dejan dominar por sus depravados instintos, es evidente que si vivieran fuera de la comunidad política, sin que hubiera un poder público superior que los pudiera coercer y reprimir, serían innumerables las matanzas, revoluciones, rapiñas, hurtos, dolos y fraudes, opresión de los débiles por los poderosos, y sería mucho peor la condición y miseria del género humano (Luis de Molina, 1975, pp. 680 y 688).

Parece claro que en una situación como la descrita por Molina es aplicable la reflexión de Hobbes de que «no hay lugar para el trabajo ya que el fruto del mismo se presenta como incierto; $y$, consecuentemente no hay cultivo de la tierra [...] y lo peor de todo, hay un constante miedo y un constante peligro de perecer con muerte violenta. Y la vida del hombre es solitaria, pobre, desagradable, brutal y corta» (Hobbes, 1991, pp. 107-108).

Y como señala Suárez en su defensa de la necesidad de las leyes, la consecuencia es que

nunca pueden mantenerse la paz y la justicia sin leyes convenientes [ya que] los hombres individuales y ordinarios encuentran difícil entender lo que es necesario para el bien común y casi nunca hacen un intento por buscarlo ellos mismos [...] dado que los hombres en su mayoría son inclinados al mal y se dejan guiar por sus pasiones, y por eso lo más frecuente es tener que reprimirlos por el temor al castigo (Suárez, 1967, p. 20 y p. 81).

La propensión del hombre a «mirar sólo por sí mismo» junto con su flaqueza moral inducen a Suárez a pintar un cuadro igual de sombrío que el de Molina, pues sin una comunidad política faltarían «todos los servicios y oficios necesarios para la vida humana, y mucho menos» podría conseguirse

el conocimiento de todas las cosas necesarias. Además, si todas las familias estuviesen divididas entre sí, apenas podría conservarse la paz entre los hombres, ni podrían rechazarse ni vengarse las injusticias de una manera ordenada [...] porque como dice el sabio: donde no hay gobierno va el pueblo a la ruina. [...] Sin el poder para gobernarla habría la mayor confusión en la comunidad (Suárez, p. 198) 
No cabe duda que tanto Suárez como Molina sostienen que es el interés propio lo que mueve a los hombres a renunciar a su libertad natural a favor de un poder público gobernado por el derecho positivo, pues como afirma Suárez:

cada uno de los miembros particulares mira por su conveniencia particular, la cual muchas veces es contraria al bien común, y a veces hay muchas cosas que son necesarias para el bien común, las cuales no son tan necesarias para cada uno de los particulares, y aunque a veces sean necesarias no se procuran porque sean de interés común sino porque son de interés particular; luego en una comunidad es necesario el poder público al cual por oficio corresponda buscar y procurar el bien común (Suárez, p. 199)

La semejanza de estos textos con los de Hobbes no puede ser más evidente. Aunque Domingo de Soto O.P. (1494-1560) tiene una concepción de la naturaleza humana muy similar a la de Suárez y Molina, sin embargo, sigue a su maestro Francisco de Vitoria y resalta que «el hombre, efectivamente, es un animal social». Pero a partir de aquí el razonamiento es prácticamente idéntico al de los jesuitas, porque «encerrar en una sociedad común la vida de los hombres es imposible mientras no haya una autoridad pública que los domine en paz, pues esta autoridad es la encargada tanto de conservar la sociedad como de administrar justicia» (De Soto, 1967, p. 309).

Una vez formada la sociedad a fin de que pueda gobernarse, rechazar a los enemigos y reprimir a los malhechores, es necesario elegir «magistrados a quien traspasar su autoridad, pues de otro modo la sociedad entera, sin orden y sin cabeza, no [...] podría proveer de todo lo que fuera conveniente» (De Soto, p. 302). Ahora bien, «para que una sociedad instituya un rey, o un emperador, a quien traspasar su autoridad, se requiere que se reúna en asamblea general, o que por lo menos la mayor parte de ella consienta en tal elección» (De Soto, p. 304). Pero además «el que gobierna tiene poder para dar leyes a fin de someter con ellas a la sociedad» (De Soto, p. 302). «Establecer las leyes [...] es el principal deber de quien ocupa el trono para gobernar el reino» (De Soto, p. 8). Porque «el derecho civil ha sido establecido por la voluntad de los hombres reunidos de común acuerdo» (De Soto, p. 45). No creo que sea exagerado descubrir la teoría del contrato en estos textos.

Pero además en Soto encontramos el concepto de seguridad jurídica y regulatoria, pues «la ley se establece no para que esté en vigor poco tiempo, sino para que dure largos siglos». Pues «los Estados suelen sufrir grave daño con el cambio frecuente de las leyes» (De Soto, p. 46).

De la misma forma, resalta el concepto de Justicia, cuando afirma que «La justicia es la voluntad firme e irrevocable de dar a cada uno lo suyo. [...] Así el objeto propio de la justicia es dar a cada uno su derecho» (De Soto, pp. 200-201). El papel de la Justicia es garantizar que se cumpla lo convenido. La justicia se ocupa «de ordenar el trato y comercio de los hombres» (De Soto, p. 209). Es la ley la que distingue lo justo de lo injusto (De Soto, p. 40) y la ley para que sea sólida y duradera «ha de tener por objeto encaminar a sus súbditos al bien común, [...] que consiste en la quietud, tranquilidad y paz social» (De Soto, p. 11). Las leyes han sido establecidas para "refrenar la audacia de los hombres y se ampare la inocencia contra los malos», pero también regulan «las ventas y otros contratos sin los cuales los hombres no podríamos vivir» (De Soto, pp. 37-38).

En definitiva afirma Domingo de Soto que 
las leyes humanas deben de prohibir principalmente los vicios, delitos y crímenes que privan a la sociedad de la paz y de la tranquilidad, como son los que envuelven alguna injusticia, es decir, aquellos que son contra la justicia conmutativa, como los homicidios, hurtos, adulterios, fraudes, trampas y otros semejantes. Puesto que la paz y sosiego de la nación han de ser el blanco y fin de los legisladores (De Soto, $p$. 48).

Un razonamiento similar a la hora de justificar y fundamentar el poder político lo encontramos en Alfonso de Castro (1495-1558), un franciscano que estudió Teología en Salamanca y Alcalá de Henares, y enseñó Teología en su convento de la ciudad del Tormes. La concepción democrática de Alfonso de Castro aparece diáfana en su descripción del poder político "cuyo fin es mantener en paz al pueblo» deja claro que es el pueblo su depositario, que "aunque se derive siempre de Dios, el ejercicio del mismo tiene lugar por medio del consentimiento del pueblo [...] y quien concedió tal cometido de gobierno al pueblo por este mismo hecho le dio la potestad de establecer leyes, sin las cuales el pueblo no puede ser regido adecuadamente». Pero "como [...] donde hay multitud hay confusión [...] fue conveniente la transferencia por el pueblo de esta potestad, concedida a él por derecho natural, a alguno que [...] diera leyes a todo el pueblo con las cuales pudiera llevar una vida pacífica». Castro insiste en que

por derecho natural, incluso después de la corrompida naturaleza, nadie es rey o señor del pueblo, sino que los principados o dominios poseídos justamente procedieron del consentimiento del pueblo [...] Consta que el poder del gobierno, que debe llamarse justo, se deriva del consentimiento del pueblo, de donde se sigue que el poder, que no tiene ningún origen en el consentimiento del pueblo, no debe llamarse justo sino tiránico (Sierra Bravo, 1975, pp. 651-653).

Otro tanto podemos decir de Diego de Covarrubias (1512-1577), discípulo de Martín de Azpilcueta y Francisco de Vitoria, catedrático de Derecho Canónico en Salamanca. En él encontramos un razonamiento similar en cuanto al origen y el papel del poder político al de sus contemporáneos. Según Covarrubias, «la potestad temporal y civil jurisdicción suprema, reside en la misma república, y [...] el príncipe será temporal y tendrá autoridad sobre todos los gobiernos de la república para los que haya sido elegido y constituido tal por la misma república [...] salvo que la sociedad humana haya establecido mediante pacto otra cosa distinta». Pero la sociedad humana no podrá

gobernar a los hombres, defenderse contra los enemigos y reprimir [...] a los malhechores, si no concede facultades [...] a los magistrados, príncipes y gobernadores y si no constituye jueces y guías a los que la multitud misma y todos los que componen la convivencia se sometan y obedezcan, ya que de otro modo, sin orden y sin cabeza, de ninguna manera conseguirían lo que se necesita para el bien de toda la comunidad (Covarrubias y Leyva, 1957, p. 248 y pp. 250-251).

En resumen, para Covarrubias el sujeto natural de la soberanía es el pueblo constituido en Estado. Es el mismo pueblo o los que le representan, quienes eligen al rey o soberano. Aunque el poder es necesario o natural, sólo el pueblo por consentimiento expreso o tácito puede determinar las condiciones del régimen político, pues el poder de los gobernantes tiene su origen en el contrato o pacto de los ciudadanos, de ahí que el poder de gobernar proceda directamente del pueblo a través del consentimiento de la mayoría de sus representantes (Luciano Pereña, 1963, p. LXXI).

Una figura representativa de esta época y de este pensamiento fue Vázquez de Menchaca (1512-1569), un jurista laico que había nacido en Valladolid en 1512 y, tras una apretada carrera profesional de alto funcionario público, moriría en 1569 en 
Sevilla, en cuya catedral era canónigo lectoral, una especie de asesor jurídico del cabildo catedralicio. Vázquez de Menchaca, a la hora de justificar la organización social y el poder político se hace eco de la concepción más negativa de la naturaleza humana, con expresiones tales como el hombre es un lobo para el hombre, o «la más funesta ruina de los hombres es solamente su semejante» (Vázquez de Menchaca, 1931-1934, p. 54). En el más puro estilo agustiniano resalta la propensión del género humano a dominar y tiranizar a los otros y el amor propio como característica de la naturaleza humana, pues «la naturaleza ha dispuesto las cosas de tal forma que todos prefieren su propio bien al de los demás»; en definitiva, la comunidad política es el resultado de individuos que se comportan como mezquinos tiranos consumidos por su propio interés, que viven en constante miedo de perder sus bienes y se ven obligados a organizarse en sociedad que ellos inventaron para su propia conveniencia y utilidad y para protegerse de sus hábitos de codicia y cobardía.

«Por su parte, la vida social reclama y pide la existencia de autoridad [...] ya en razón de la propensión del género humano a la disensión, según es de todos conocido, ya principalmente porque todos los hombres hasta tal punto son propensos a la tiranía, o por lo menos al aprecio de sí mismos, que llevados de la naturaleza todos anteponen el bien propio al de los demás» (Vázquez de Menchaca, pp. 52-53). Y por otra parte, «siendo la vida social y común origen de discordias, es necesario para apaciguar estas divisiones y contiendas el que existan magistrados, para que de otro modo no se lancen a cada paso los hombres a pendencias, tumultos sediciosos, rapiñas, luchas, y a las sangrientas armas» (Vázquez de Menchaca, p. 52).

Vázquez de Menchaca justifica el poder político como algo creado por los propios individuos que renuncian a sus conveniencias para su utilidad y de esta forma pasar la vida de un modo más conveniente (Vázquez de Menchaca, p. 53).

Una figura menos conocida en el ámbito de la filosofía política pero de gran interés es la de Fray Luis de León (1527-1591) y su teoría de la sociedad política, tal y como aparece en el Tratado sobre la ley (De Legibus), esto es, las lecciones que impartió Fray Luis en el curso 1570-1571 desde su cátedra de Durando en la universidad de Salamanca. Según Fray Luis, el poder político surge de la necesidad de encauzar la actividad de los ciudadanos al fin propio del Estado que es garantizar el bien común. La función de la autoridad es procurar y defender el bien público de su comunidad y en esto consiste la finalidad de la ley. El rey debe promulgar leyes para el bien del Estado y utilidad pública, para que los ciudadanos vivan en paz y tranquilidad. Dice Fran Luis de León que:

Los reyes, si en verdad son reyes, tienen todo su poder y todo su derecho de dominio proveniente de la república, pues el mandar supremamente sobre otros no lo poseen los reyes por naturaleza, sino que por consentimiento, expreso o tácito, del pueblo se produjo el que uno solo rigiese a los demás y les administrase justicia; pero la propia razón muestra que ninguna república y ningún consentimiento del pueblo ha dado a los reyes un dominio tan pleno sobre los bienes de cada uno de los súbditos...porque la república y el pueblo constituyeron al rey por propio provecho de ellos, y no a causa de la utilidad del príncipe, es decir, constituyó al rey para esto para poner a salvo de la justicia a cada ciudadano; no, pues, para despojar a cada uno de ellos de sus propios bienes; y lo instituyó para que hiciera felices y dichosos a los súbditos; no, pues, para que los hiciera desdichados (Fray Luis de León, 2005, pp.107 y 109)

La ley es el instrumento que utiliza el poder político que dirige la comunidad para cumplir con sus funciones y conseguir sus objetivos, y puesto que la función 
propia de la autoridad política es procurar y proteger el bien público de la comunidad que preside, entonces toda ley se ordena a la consecución del bien público. De ahí que según adelantábamos más arriba, Fray Luis concluya citando a Cicerón, Platón y el Decreto de Graciano, que los gobernantes promulgan «leyes para el bienestar de los ciudadanos, para su conservación y para la vida tranquila y feliz de los hombres» en razón de la paz y utilidad pública. Ello implica que los gobernantes no pueden atentar contra los intereses legítimos de los ciudadanos pues el único fin del rey es procurar la felicidad y prosperidad de estos.

\section{Bibliografía}

Covarruvias y Leyva, D. (1957). Textos jurídicos-políticos. Selección y prólogo de Manuel Fraga Iribarne. Madrid, España: Colección Civitas.

Deane, H. A. (1963). The Political and Social Ideas of ST. Augustine. Columbia, EE.UU: Columbia University Press.

De Molina, L. (1941). Los seis libros de la Justicia y del Derecho. Traducción, estudio preliminar y notas de Manuel Fraga Iribarne. Madrid, España: Facultad de Derecho de la Universidad Complutense.

De Soto, D. (1967). De la justicia y del Derecho en Diez Libros. Madrid, España: Instituto de Estudios Políticos.

De Vitoria, F. (1960). Obras de Francisco de Vitoria. Madrid, España: Biblioteca de Autores Cristianos.

Fray Luis de León (2005). Tratado sobre la Ley. Introducción, transcripción y notas por José Barrientos García. Real Monasterio de El Escorial, España: Ediciones Escurialenses.

Fray Luis de León (1963). De Legibus o Tratado de las leyes 1571. Madrid, España: Consejo Superior de Investigaciones Científicas.

Hobbes, T. (1991). Leviathan. Cambridge, UK: Cambridge University Press.

Martín Martín, V. (2011). Teoría del Estado y Derechos de Propiedad en la Escolástica Española del siglo XVI. Un antecedente de la Nueva Economía Institucional. Revista del Instituto de Estudios Económicos, (2), pp. 81-110.

Martín Martín, V. (2002). El Liberalismo Económico. Madrid, España: Editorial Síntesis.

Pereña, L. (1963). Introducción. En Fray Luis de León, De Legibus o Tratado de las leyes 1571. Madrid, España: Consejo Superior de Investigaciones Científicas.

San Agustín (1982). Obras Completas. Madrid, España: Biblioteca de Autores Cristianos.

Sierra Bravo, R. (1975). El pensamiento social y económico de la Escolástica. Desde sus orígenes al comienzo del catolicismo social. Vol. II. Madrid, España: Instituto de Sociología «Balmes»-Consejo Superior de Investigaciones Científicas.

Suárez, F. S. J. (1967). Tratados de las Leyes y de Dios legislador, en Diez Libros. Madrid, España: Instituto de Estudios Políticos.

Vázquez de Menchaca, F. (1931-1934). Controversiarum illustrium aliarumque usu frequentium libri tres. Notas y traducción de Fidel Rodríguez Alcalde. Prólogo de Calixto Valverde y Valverde. Valladolid, España: Talleres Tipográficos «Cuesta». 